\title{
NOTES
}

\section{Synthesis of New Poly(enaryloxynitrile)s Containing Flexible Ether Units and Thermal Properties}

\author{
Jung-Hyup HA, Byung-Gu KIM, Chulhee KIM, ${ }^{*}$ \\ and Myoung-Seon $\mathrm{GoNG}^{\dagger}$ \\ Department of Chemistry, Dankook University, \\ Cheonan 330-714, Chungnam, Korea \\ * Department of Polymer Science \& Engineering, Inha University, \\ Incheon 402-751, Korea
}

(Received August 15, 1994)

KEY WORDS Poly(enaryloxynitriles) / Thermally Stable Polymers Thermally Curable Polymers / Dicyanovinyl Group / Flexible Ether Units /

Recently, much interest has been devoted to the study of rigid chain polymers, mainly due to their excellent mechanical and thermal properties. Most of these polymers form mesogenic shases on heating or dissolving. However, their infusibility and insolubility make them inaccessible for processing by conventional methods. To enhance the processibility of these materials, several approaches have been attempted. The introduction of cyclic aromatic groups lying perpendicular to the backbone, crank shaft-shaped and flexible units into the main chain have been used. ${ }^{1-4}$

Aromatic $^{5-7}$ and aliphatic ${ }^{8-10}$ poly(enaminonitrile)s and poly(enaryloxynitriles) ${ }^{1-13}$ prepared from $p$-bis(1-chloro-2,2-dicyanovinyl)benzene and amines or diphenols are soluble in polar aprotic solvents. Tractability has been achieved by lowering melting temperature by the insertion of flexible units into the rigid backbone.

A variety of structural modification allows the chain stiffness that can be altered from a relatively flexible polymer with a low glass transition temperature to a rodlike molecule with a high $T_{\mathrm{g}}$. The incorporation of the flexible alkylenic ether chain enhances the solubility in common organic solvents and decreases the melting temperature of poly(enaryloxynitriles).

In this paper, we report a series of poly(enaryloxynitrile)s with flexible alkylenic ether units distributed on a diphenol moiety and their thermal properties.

\section{EXPERIMENTAL}

1-Chloro-1-phenyl-2,2-dicyanoethene (1) and $p$-bis(1-chloro-2,2-dicyanovinyl)benzene (2) were prepared by the method previously reported by Moore and coworkers. ${ }^{5} \alpha, \omega$-Bis(4hydroxyphenoxy)alkanes were synthesized according to a method described by Griffin and Havens. ${ }^{14}$ 1,2-Dichloroethane was purified by the conventional purification method. FT-IR spectra were obtained with a Midac spectrophotometer and ${ }^{1} \mathrm{H}$ NMR spectra were recorded on a Varian EM-360A spectrometer. Elemental analyses were obtained with a Yanaco MT-3 CHN-analyzer. GPC data were obtained with a Waters HPLC using three columns ( $\mu$-Styragel $10^{2}, 10^{3}$, and $10^{4} \AA$ ) in tetrahydrofuran and calibrated with poly-

\footnotetext{
$\uparrow$ To whom correspondence should be addressed.
} 
styrene standards. Theremal analyses of polymers were carried out on a Du Pont 2100 and a Mettler thermal analyzer at a heating rate of $10^{\circ} \mathrm{C} \mathrm{min}^{-1}$ under nitrogen.

\section{Preparation of 1-(4-Methoxyphenyl)-1-phenyl-} 2,2-dicyanoethene (3)

p-Methoxyphenol $(0.66 \mathrm{~g}, 5.0 \mathrm{mmol})$ dissolved in a solution of sodium hydroxide $(0.22 \mathrm{~g}, 5.5 \mathrm{mmol})$ in distilled water $(20 \mathrm{ml})$ was placed in a blender jar and a solution of $1(1 \mathrm{~g}$, $5.3 \mathrm{mmol}$ ) in $20 \mathrm{ml}$ of 1,2-dichloroethane was added quickly to the jar. After the blender was operated at full speed for $5 \mathrm{~min}$, the organic layer was separated and the solvent was evaporated. The white solid product was filtered, washed with distilled water several times, and recrystallized from isopropyl alcohol.

A similar procedure was applied for the synthesis of the model compound $\mathbf{4}$ by reacting two equivalents of 1 with disodium salts of 1,2-bis(4-hydroxyphenoxy)ethane.

\section{1-(4-Methoxyphenoxy)-1-phenyl-2,2-dicyano- ethene (3)}

Yield $94 \%, \mathrm{mp} 111^{\circ} \mathrm{C}$ (uncorrected).

FT-IR (KBr): 3120, $2970 \quad(\mathrm{C}-\mathrm{H}), 2225$ $(\mathrm{C} \equiv \mathrm{N}), 1578(\mathrm{C}=\mathrm{C})$, and $1300-1150(\mathrm{C}-\mathrm{O})$ $\mathrm{cm}^{-1}$.

${ }^{1} \mathrm{H} \mathrm{NMR}\left(\mathrm{CDCl}_{3}\right): \delta=7.5(\mathrm{~m}, 5 \mathrm{H}, \underline{\mathrm{Ph}}-), 6.8$ (s, $4 \mathrm{H}, \mathrm{CH}_{3} \mathrm{O}-\mathrm{Ph}-$ ), 3.5 (s, 3H, $\mathrm{CH}_{3} \mathrm{O}_{-}$).

Anal. Calcd for $\left(\mathrm{C}_{17} \mathrm{H}_{12} \mathrm{~N}_{2} \mathrm{O}_{2}\right): \mathrm{C}, 73.91 \%$; $\mathrm{H}, 4.35 \%$; N, 10.14\%. Found: C, $72.98 \%$; $4.27 \%$; N, $10.06 \%$.

\section{1,2-Bis[4-(1-phenyl-2,2-dicyanovinyloxy)phe- noxy] ethene (4) \\ Yield $92 \%$, mp $227^{\circ} \mathrm{C}$ (uncorrected).}

FT-IR (KBr): $3110-2985$ (aromatic C-H), 2980-2865 (C-H), $2221(\mathrm{C} \equiv \mathrm{N}), 1580(\mathrm{C}=\mathrm{C})$, and $1300-1150(\mathrm{C}-\mathrm{O}) \mathrm{cm}^{-1}$.

${ }^{1} \mathrm{H}$ NMR $\left(\mathrm{CDCl}_{3}+\right.$ dimethyl solfoxide (DMSO)- $d_{6}$ ): $\delta=7.5(\mathrm{~m}, 10 \mathrm{H}, 2 \mathrm{Ph}-), 6.9$ (q, $8 \mathrm{H}, 2-\mathrm{O}-\mathrm{Ph}-\mathrm{O}-), 4.2$ (s, $4 \mathrm{H},-\mathrm{CH}_{2} \mathrm{CH}_{2}-$ ).

Anal. Calcd for $\left(\mathrm{C}_{34} \mathrm{H}_{22} \mathrm{~N}_{4} \mathrm{O}_{4}\right)$ : C, $74.18 \%$; $\mathrm{H}, 4.00 \%$; N, 10.18\%. Found: C, $75.02 \%$; ,
$3.92 \% ; \mathrm{N}, 10.01 \%$.

Gerneral Procedure of Polymerization of 2 with Disodium Salts of $\alpha, \omega$-Bis(4-hydroxyphenoxy)alkane

A solution of $2(1 \mathrm{~g}, 3.3 \mathrm{mmol})$ and $5 \mathrm{~mol} \%$ of tetra- $n$-butylammonium chloride in $20 \mathrm{ml}$ of 1,2-dichloroethane was transferred to the blender jar. Disodium salts of 1,4-bis(4-hydroxyphenoxy)butane $(0.96 \mathrm{~g}, 3.3 \mathrm{mmol})$ in distilled $(20 \mathrm{ml})$ water were added to the blender and the reaction mixture was sitrred at full speed for $5 \mathrm{~min}$. A powdery polymer was precipitated immediately, and the reaction mixture was stirred for an additional $3 \mathrm{~min}$. The polymer was isolated from the jar and rinsed with large amounts of distilled water. The powdery product was replaced in the jar with $30 \mathrm{ml}$ of water and a few drops of $1 N \mathrm{HCl}$, and blended to a fine powder, filtered and dried under vacuum at $60^{\circ} \mathrm{C}$ for $12 \mathrm{~h}$.

5: FT-IR (KBr): 3120, $2910(\mathrm{C}-\mathrm{H}), 2218$ $(\mathrm{C} \equiv \mathrm{N}), 1575(\mathrm{C}=\mathrm{C})$, and $1360-1145(\mathrm{C}-\mathrm{O})$ $\mathrm{cm}^{-1}$.

${ }^{1} \mathrm{H}$ NMR (DMSO- $d_{6}+\mathrm{CDCl}_{3}$ ): $\delta=7.5(\mathrm{br}$, $4 \mathrm{H}$, aromatic $\mathrm{H}$ 's in 2$), 6.8(\mathrm{br}, 8 \mathrm{H}$, aromatic H's in diphenol), 3.8 (br, $4 \mathrm{H},-\mathrm{OCH}_{2} \mathrm{CH}_{2} \mathrm{O}-$ ).

Anal. Calcd for $\left(\mathrm{C}_{28} \mathrm{H}_{16} \mathrm{~N}_{4} \mathrm{O}_{6}\right)_{n}$ : C, $71.19 \%$; $\mathrm{H}, 3.39 \%$; N, $11.86 \%$. Found: C, $71.77 \%$; H, $3.31 \%$; N, $11.45 \%$.

6: FT-IR (KBr): 3122, $2915(\mathrm{C}-\mathrm{H}), 2220$ $(\mathrm{C} \equiv \mathrm{N}), 1578(\mathrm{C}=\mathrm{C})$, and $1300-1120(\mathrm{C}-\mathrm{O})$ $\mathrm{cm}^{-1}$.

${ }^{1} \mathrm{H}$ NMR (DMSO- $d_{6}+\mathrm{CDCl}_{3}$ ): $\delta=7.5(\mathrm{br}$, $4 \mathrm{H}$, aromatic $\mathrm{H}$ 's in 2$), 6.8(\mathrm{br}, 8 \mathrm{H}$, aromatic H's in diphenol), 3.8 (br, $4 \mathrm{H},-\mathrm{OCH}_{2} \mathrm{CH}_{2} \mathrm{CH}_{2}$ $\mathrm{CH}_{2} \mathrm{O}-$ ), 1.8 (br, $4 \mathrm{H},-\mathrm{OCH}_{2} \mathrm{CH}_{2} \mathrm{CH}_{2} \mathrm{CH}_{2} \mathrm{O}-$ ).

Anal. Calcd for $\left(\mathrm{C}_{30} \mathrm{H}_{20} \mathrm{~N}_{4} \mathrm{O}_{4}\right)_{n}$ : C, $72.00 \%$; $\mathrm{H}, 4.00 \%$; N, $11.20 \%$. Found: C, $72.31 \%$; $\mathrm{H}$, $4.11 \% ; \mathrm{N}, 10.87 \%$.

Other poly(enaryloxynitrile)s with flexible alkylenic chain showed similar IR and NMR spectra as described above. 


\section{RESULTS AND DISCUSSION}

The reactivity of phenoxide anions toward dicyanovinyl chloride was determined according to the $\mathrm{p} K_{\mathrm{a}}$ of the corresponding phenol derivative. A comparison of $\mathrm{p} K_{\mathrm{a}}$ of $p$-methoxyphenol with that of phenol $\left(\mathrm{p} K_{\mathrm{a}}\right.$ 10.0) indicates that an electron donating methoxy group at para-position enhances reactivity to dicyanovinyl chloride. $\alpha, \omega$-Bis(4-hydroxyphenoxy)alkanes in this work possess $\mathrm{p} K_{\mathrm{a}}$ of $10.23,{ }^{15}$ which shows appreciable reactivity to dicyanovinyl chloride.

Polymerization was based on a representative procedure for interfacial polymerization in the presence of a phase transfer catalyst. Model compounds resembling the repeating unit of polymers were prepared for demonstration of the feasibility of polymer formation and comparison with polymers. Two different model compounds, 1-(4-methoxyphenoxy)-1phenyl-2,2-dicyanoethene (3) and 1,2-bis[4-(1phenyl-2,2-dicyanovinyloxy)phenoxy]ethane (4) were prepared by reacting $p$-methoxyphenol and 1,2-bis(4-hydroxyphenoxy)ethane with 1 as shown in Scheme 1.

The sodium methoxyphenoxide reacted so

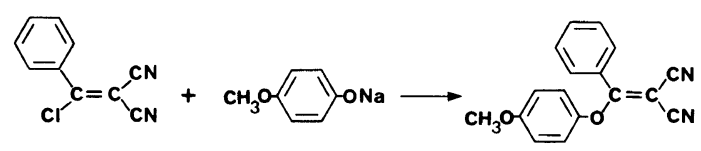

1

3
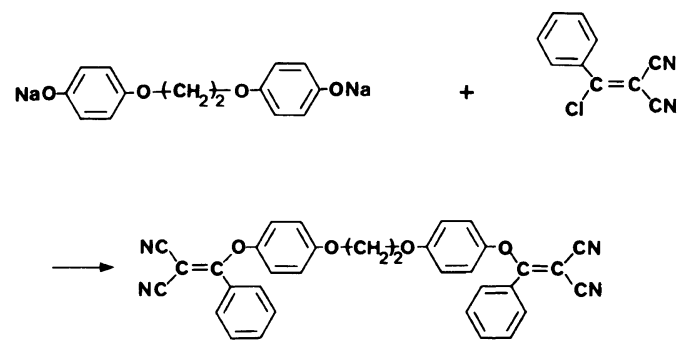

4

Scheme 1. rapidly with 1 in two phase solvent system that the reactions were almost complete within $5 \mathrm{~min}$ at room temperature. After recrystallization, a $94 \%$ yield of 1-(4-methoxyphenyl)-2,2dicyanoethene (3) was obtained. Similarly, the condensation of diphenol compound, 1,2bis(4-hydroxyphenoxy)ethane with 1 was investigated and found to proceed at room temperature to give 1,2-bis[4-(1-phenyl-2,2dicyanovinyloxy)phenoxy]ethane (4) in $92 \%$ yield.

Infrared spectra of model compounds 3 and 4 showed absorption bands at 3120, 2910, and $2218 \mathrm{~cm}^{-1}$ assignable to $\mathrm{C}-\mathrm{H}$ and $\mathrm{C} \equiv \mathrm{N}$, as well as two characteristic bands of $\mathrm{C}=\mathrm{C}$ and $\mathrm{C}-\mathrm{O}$ at 1575 and $1360-1115 \mathrm{~cm}^{-1}$, respectively.

In the NMR spectrum, model compound 3 showed peaks at $7.5 \mathrm{ppm}$ corresponding to aromatic proton of fragment of $\mathbf{1}$, while the peak of aromatic protons of phenol unit appeared at $6.8 \mathrm{ppm}$. The polymers obtained here were identified as poly(enaryloxynitrile)s by IR and NMR spectroscopy. The infrared spectra of the polymers were consistent with their assigned chemical structures and corresponded well with the spectra of the model compounds. Representative NMR spectra of the polymers and model compound $\mathbf{4}$ are given in Figure 1.

The condensation of $\mathbf{2}$ with sodium salts of various diphenol derivatives was carried out by the interfacial polymerization ${ }^{15}$ as shown in Scheme 2.

Table I summarizes the results of the polymerization of 2 with sodium salts of diphenol derivatives. Poly(enaryloxynitrile)s derived from flexible diphenol derivatives showed good solubility in polar aprotic solvents such as DMF, DMAc, DMSO, and NMP, and were soluble even in acetone and tetrahydrofuran. Poly(enaryloxynitrile)s 5 and $\mathbf{6}$ with short alkylenic ether chains were somewhat less soluble than those derived from long chain alkylenic chains in common organic solvents. The polymers possess $M_{n}$ in the range of 


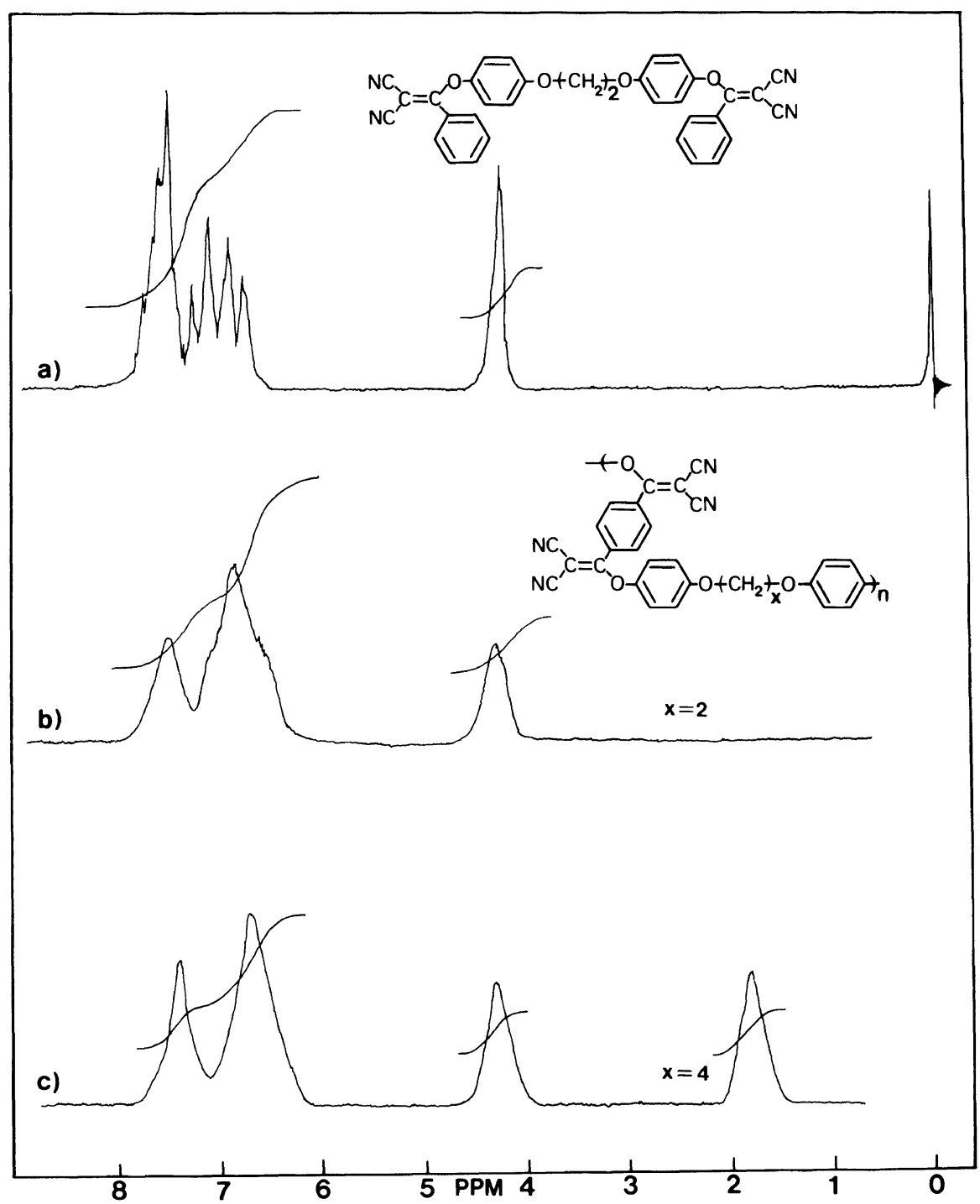

Figure 1. ${ }^{1} \mathrm{H}$ NMR spectra of a) model compound 4, and b), c) poly(enaryloxynitriles) prepared from 2 and 1,2-bis(4-hydroxyphenoxy)ethane and 1,4-bis(4-hydroxyphenoxy)buthane.

$3000-5500$ and $M_{w}$ in the range of 9000 14000. A film cast from a THF solution of polymer $\mathbf{8}$ was transparent and brittle, which could be due to rather low molecular weight.

The polymers showed interesting differential scanning calorimograms as shown in Figure 2. The DSC thermogram of the polymers showed a large exotherm at around $370^{\circ} \mathrm{C}$, which did not reappear upon rescanning the sample. The polymers derived from long chain alkylenic chain showed a trace of an endothermic peak, which implies that a high proportion of amorphous domain existed in the polymer structure. This was evidenced by X-ray diffractograms obtained from the polymerized sample powders in a deflection mode. On the other hand, polymers 5 and $\mathbf{6}$ with short chains exhibited well-defined melting transition at 308 


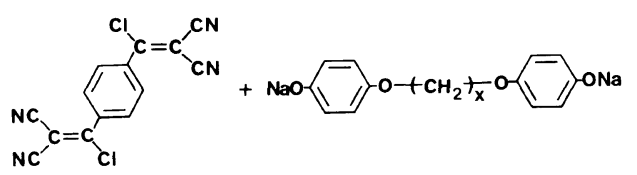

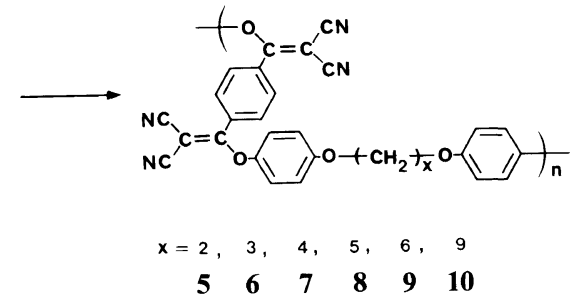

Scheme 2.

Table I. Results and conditions of the polymerization of $\mathbf{2}$ with disodium salts of diphenol derivatives

\begin{tabular}{|c|c|c|c|c|}
\hline \multirow{2}{*}{ Polymer $^{a}$} & \multirow{2}{*}{$-\left(\mathrm{CH}_{2}-\right)_{n}-$} & Yield & \multirow{2}{*}{$M_{n}$} & \multirow{2}{*}{$M_{w}$} \\
\hline & & $\%$ & & \\
\hline 5 & 2 & 90 & 3600 & 14400 \\
\hline 6 & 3 & 92 & 5700 & 11200 \\
\hline 7 & 4 & 86 & 4200 & 12600 \\
\hline 8 & 5 & 84 & 3470 & 13800 \\
\hline 9 & 6 & 83 & 5400 & 10800 \\
\hline 10 & 9 & 95 & 2970 & 9000 \\
\hline
\end{tabular}

a Polymerizations were carried out for $5 \mathrm{~min}$ at room temperature, using the 1,2-dichloroethane/water system. and $320^{\circ} \mathrm{C}$, rspectively.

Thermal gravimetric analysis results are shown in Figure 3 and Table II. The aliphatic $\mathrm{C}-\mathrm{H}$ bond has a low dissociation energy compared with an aromatic one and hence polymers having aliphatic units in the main

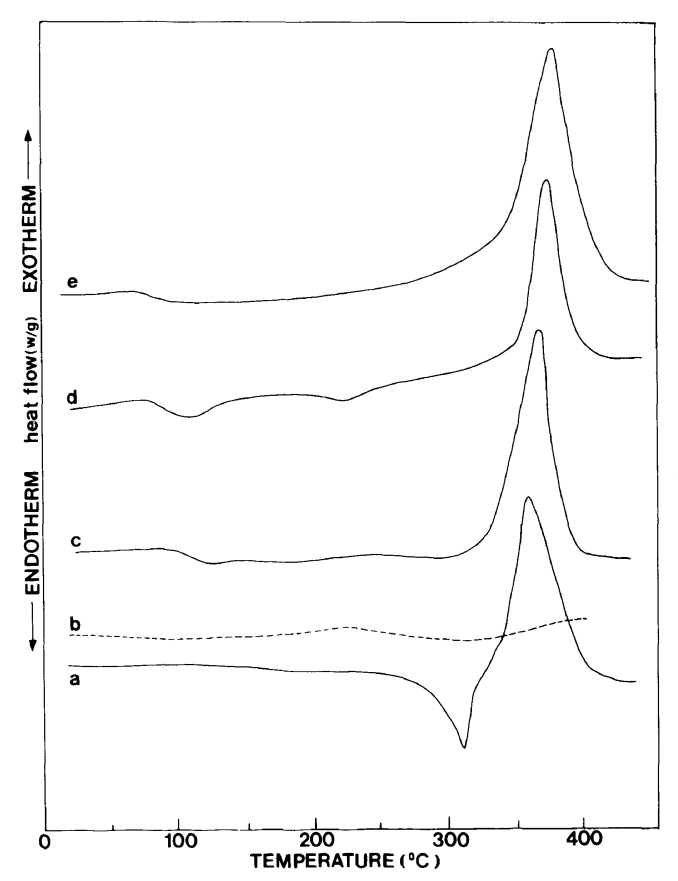

Figure 2. DSC thermograms of polymers of a) 5 (1st scan), b) 5 (2nd scan), c) 7, d) 9, and e) 10.

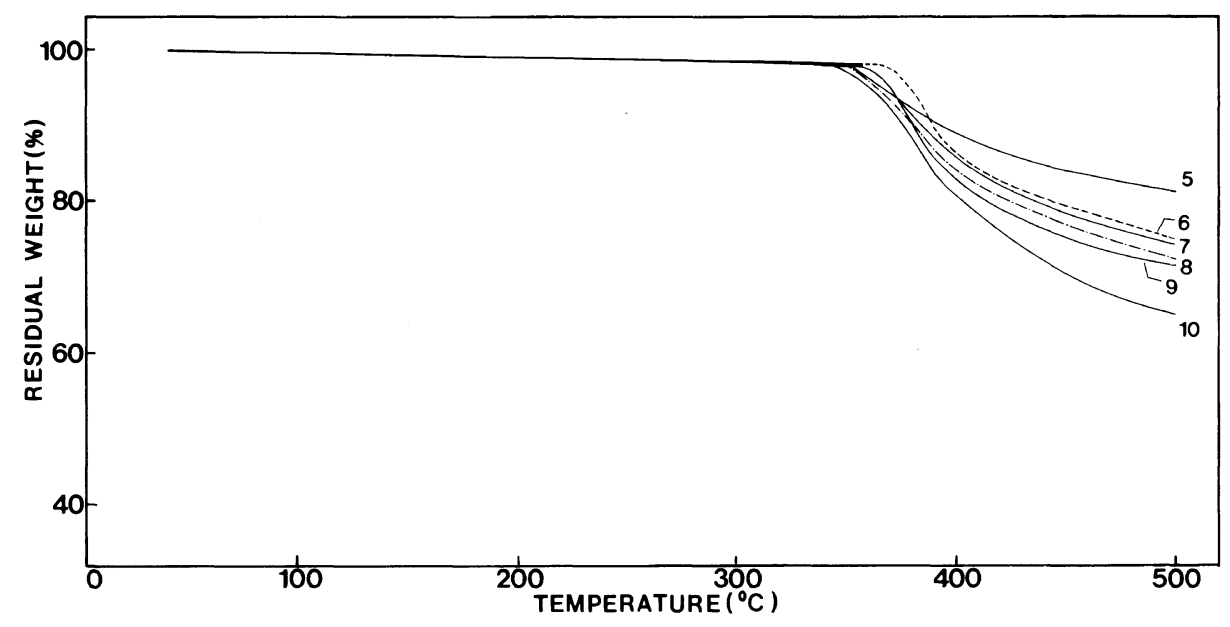

Figure 3. TGA traces of poly(enaryloxynitrile)s under nitrogen atmosphere. 
Table II. Thermal properties of poly(enaryloxynitrile)s with flexible alkylenic ether units

\begin{tabular}{|c|c|c|c|c|c|c|c|}
\hline \multirow{2}{*}{ Polymer } & \multirow{2}{*}{$-\left(\mathrm{CH}_{2}-\right)_{n}^{-}$} & \multirow[t]{2}{*}{$T_{\mathrm{g}}$} & \multirow{2}{*}{$\begin{array}{l}\text { Endo } \\
{ }^{\circ} \mathrm{C}\end{array}$} & \multirow[t]{2}{*}{ Exo } & \multirow{2}{*}{$\begin{array}{c}10 \% \text { Weigt } \\
\text { Loss } /{ }^{\circ} \mathrm{C}\end{array}$} & \multicolumn{2}{|c|}{ Residual weight $/ \%$} \\
\hline & & & & & & $400^{\circ} \mathrm{C}$ & $500^{\circ} \mathrm{C}$ \\
\hline 5 & 2 & - & 314 & 355 & 393 & 89 & 81 \\
\hline 6 & 3 & 174 & 323 & 394 & 392 & 85 & 77 \\
\hline 7 & 4 & 106 & - & 368 & 389 & 87 & 77 \\
\hline 8 & 5 & 116 & - & 362 & 386 & 86 & 74 \\
\hline 9 & 6 & 96 & - & 377 & 382 & 83 & 72 \\
\hline 10 & 9 & 78 & - & 385 & 368 & 80 & 67 \\
\hline
\end{tabular}

chain do not usually show high thermal stability. However, polymers sustained a $90 \%$ residual weight at the temperature between $370^{\circ} \mathrm{C}$ and $390^{\circ} \mathrm{C}$ and $75-80 \%$ of residual weight at $500^{\circ} \mathrm{C}$. Within each series, greater thermal stability was observed in the case of polymers with shorter alkylenic chains. A sample of a polymer heated around $350^{\circ} \mathrm{C}$ corresponding to the beginning of its exotherm, displayed a gradual change in its IR spectra. The band of uncured polymer at $2235 \mathrm{~cm}^{-1}$. assignable to $\mathrm{C} \equiv \mathrm{N}$ was remarkably reduced, while bands at around $1580 \mathrm{~cm}^{-1}$ were broadened and $\mathrm{N}-\mathrm{H}$ stretching band appeared at around $3400 \mathrm{~cm}^{-1}$. After the polymer was heated, the previously soluble sample was completely insoluble in THF and DMF. This observation may be due to the chemical change of dicyanovinyl group to other functions such as $\mathrm{C}=\mathrm{N}$ and $\mathrm{N}-\mathrm{H}$ by intra or intermolecular addition or corss-linking reaction. ${ }^{5,12}$ Enhanced thermal stability is associated with a dicyanovinyl group in the polymer chain.

On the bases of these results, the chemical structures of polymers changed during heating to $390^{\circ} \mathrm{C}$ at most. However the decomposition of polymer seems to occur simultaneously during crosslinking of the dicyanovinyl group.

\section{REFERENCES}

1. J. Preston, Angew. Makromol. Chem, 1 (1982).

2. M. Ballauff, Angew. Chem. Int. Ed. Engl., 28, 2531 (1989).

3. J. Majnusz, J. M. Catala, and R. W. Lenz, Eur. Polym. J., 19, 1043 (1983).

4. W. R. Krigbaum, H. Hakemi, and R. Kotek, Macromolecules, 18, 965 (1985).

5. J. A. Moore and D. R. Robello, Macromolecules, 22, 1084 (1989).

6. J. A. Moore and D. R. Robello, Macromolecules, 19, 2667 (1986).

7. J. H. Kim and J. A. Moore, Korea Polym. J., 1, 166 (1993).

8. M. S. Gong, S. T. Kim, and H. S. Moon, Macromolecules, 25, 7932 (1992).

9. M. S. Gong, S. T. Kim, J. S. Kim, and S. H. Choi, Polym. J., 25, 763 (1993).

10. M. S. Gong, B. G. Kim, and Y. S. Kim, Polym. J., 26, 1190 (1994).

11. M. S. Gong, H. S. Moon, and J. S. Kim, Polym. J., 25, 193 (1993).

12. M. S. Gong, S. H. Choi, and B. G. Kim, Macromolecules, 26, 6654 (1993).

13. M. S. Gong, S. T. Kim, and H. S. Moon, Makromol. Chem. Rapid Commun., 12, 591 (1991).

14. A. C. Griffin and S. J. Havens, J. Polym. Sci., Polym. Phys. Ed., 19, 951 (1981).

15. J. A. Dean, "Lange Handbook of Chemistry", 13th ed, McGraw Hill, New York, N.Y., 1985, pp 5-1860.

16. S. C. Temin, "Interfacial Sythesis," Vol 11, Marcel Dekker Inc., New York, N.Y., 1977. 